\title{
Analysis of photoelastic stress fields in beam
}

\author{
M. Tabanyukhova ${ }^{\text {a }}$ \\ Novosibirsk State University of Architecture and Civil Engineering (Sibstrin), Civil Mechanics \\ Department, 113 Leningradskaya st., t. Novosibirsk, 630008, Russia
}

\begin{abstract}
We have investigated the stress state of models of beams with damage in the form of cuts, simulating the vertical and inclined cracks. The experiments were performed in pure and direct lateral bending. The crack was located in the tension zone model of a beam of piezooptical plexiglass. To study was used method of the photo elasticity. Was ended collating of the stress fields in models of beams with reinforcing layer of carbon fiber and in its absence.
\end{abstract}

\section{Background}

In the last decade abroad for repair of the elements of building constructions introduced a new method - the use of the reinforcing layer to reinforce concrete. This layer is made of steel sheets, carbon fiber, etc.

Advantages of the reinforcing layer of carbon fiber are in a good resistance to external shocks, high corrosion resistance, easy of use, high strength material of the reinforcing layer.

The disadvantage is the destruction of the material of construction in the zone affixed to the supporting layer, delamination of the reinforcing layer with time. Researches, focused on studying those causes are descripted in works $[1,2,3]$.

\section{Purpose}

Model study of stress fields in the beams with the presence of damages (cracks, cuts). Assessing the impact of the reinforcing layer on the stress state near the vertical and inclined cracks-cuttings. Research of concentration tension with summits of vertical and incline cracks.

\section{Experimental}

For the research was made set of the models. It consisted of a beam of piezooptical plexiglass brand E2, which has high optical sensitivity. For this material within the span of work performed tests to determine the price band of material on stresses $\left(\sigma_{0}{ }^{1,0}=1.82 \mathrm{MPa} \bullet \mathrm{cm}\right)$. Samples were fabricated beams with crack-cuts on the vertical axis of symmetry, with a crack cutting at an angle of $45^{\circ}$ to the vertical symmetry axis (the depth of cuts in both cases was $6 \mathrm{~mm}$ ) and similar patterns of beams

a e-mail : bdtmv@mail.ru 
without damage. In pure and direct lateral bending (Fig. 1) tested the above model. Then on the lower contour of the samples with epoxy was glued layer of carbon fiber (layer thickness was $0.55 \mathrm{~mm}$, including a layer of glue). In addition, the whole procedure was repeated again.

a)

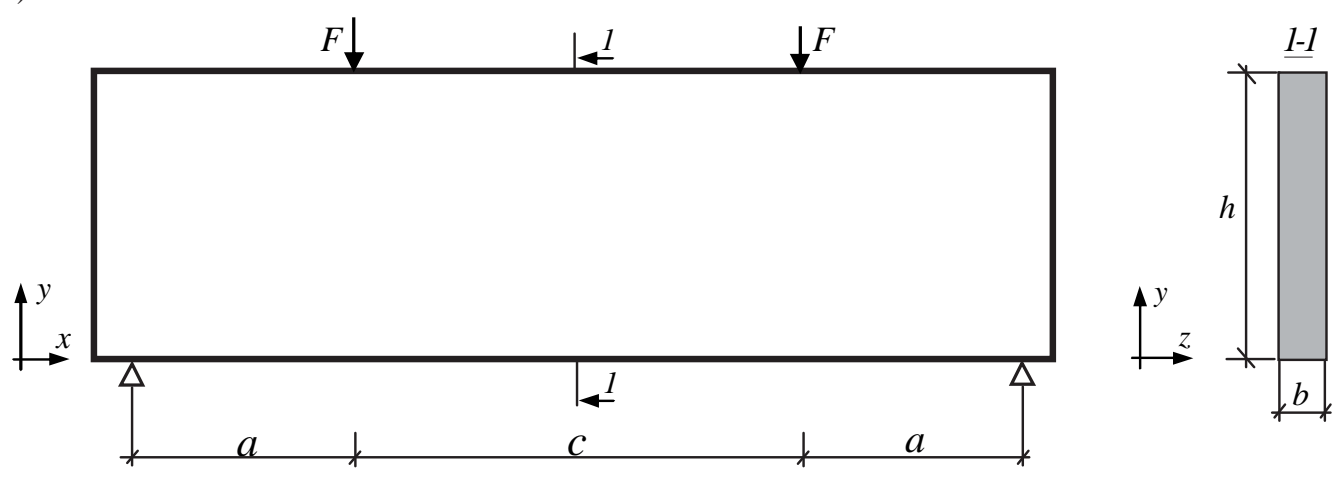

b)

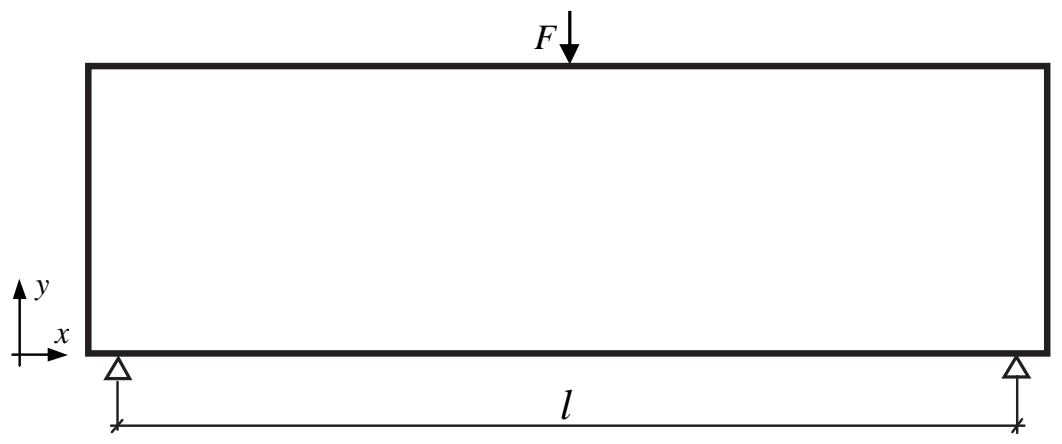

Fig. 1. Scheme loading beam: a) pure bending; b) direct cross-bending; $1=8 \mathrm{~cm}, \mathrm{~h}=1.8 \mathrm{~cm}, \mathrm{~b}=0.5 \mathrm{~cm}, \mathrm{c}=5 \mathrm{~cm}, \mathrm{a}=1.5 \mathrm{~cm}$

\section{The results of the experiment}

Using the method of photo elasticity was obtained pictures of the interference bands, which are directly related to the differences of principal stresses $\sigma_{1}-\sigma_{2}$. Figure 2 shows fragments of photographs of paintings of the interference bands in pure bending in the beam without the reinforcing layer (Fig. 2a) and in the beam with reinforcing layer of carbon fiber (Fig. 2b). Figures in the photos $1,2,3, \ldots$ - is orders of interference bands.

For pictures of the interference bands (Fig. 2) shows that the order of bands on the contour in the tension zone model of a beam with a reinforcing layer is much lower. The order of the band on lower contour of beam without carboplastic was constitute 2 (Fig. 2a), and the order of the band in the lengthy zone of the model of the beam with inforced layer is less in two ones (Fig. 2b). The introduction of carbon-fiber stress decreased by 53\% compared with the voltage in the model of the beam without the reinforcing layer. 
a)

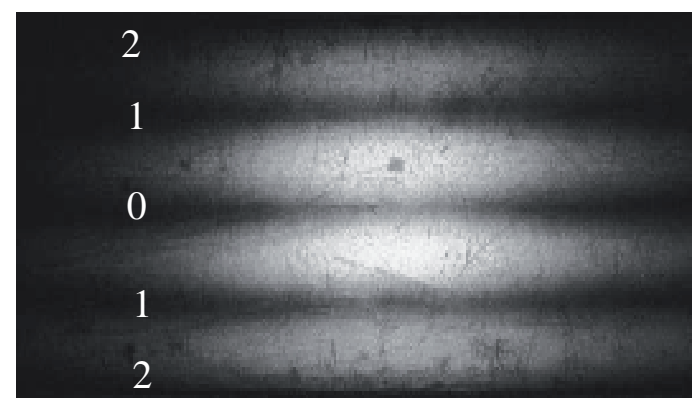

b)

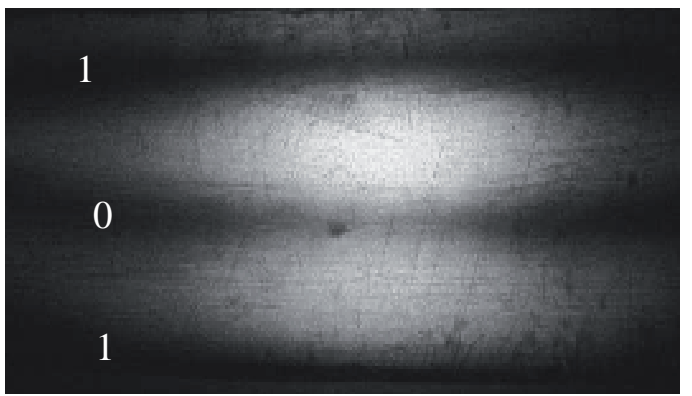

Fig. 2. Pictures of the interference bands in pure bending, $F=0,123 \mathrm{kN}$ :

a) model of the beam without carbon fiber, b) model of a beam with carbon fiber

Fig. 3 shows photographs of paintings of the interference bands in the direct lateral bending for a beam without carbon fiber(Fig. 3a) and for the sample with the supporting layer (Fig. 3b). This allows you to see the change of the stress field arising in the model with the introduction of the reinforcing layer.

a)

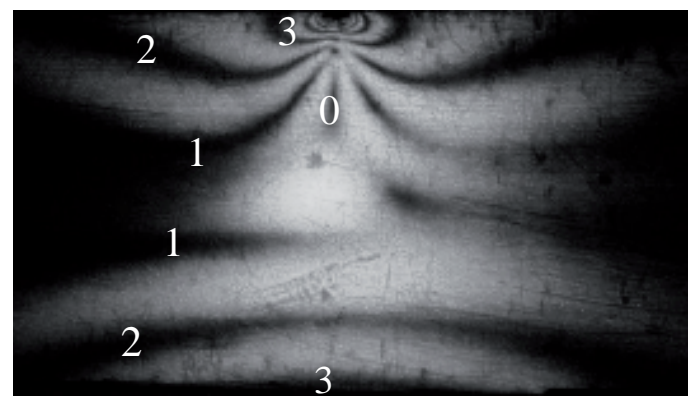

b)

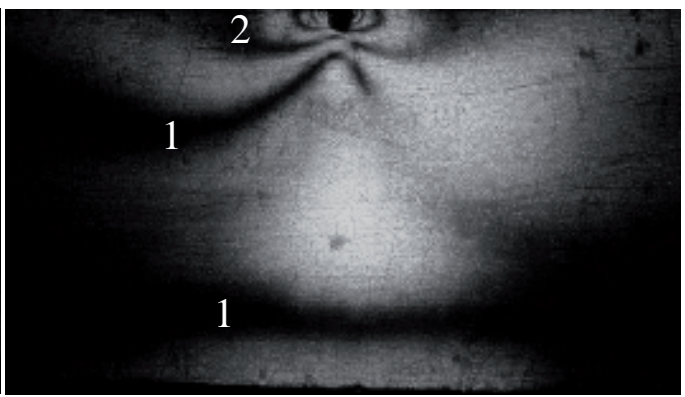

Fig. 3. Pictures of the interference bands in the direct lateral bending, $F=0,147 \mathrm{kN}$ : a) model of the beam without carbon fiber, b) model of a beam with carbon fiber

In direct lateral bending (Fig. 3) difference between the stresses on the contour model in the tension zone significantly, the difference is $55 \%$, that means: introduction of the reinforcing layer reduces the stress.

Fig. 4 and 5 shows fragments of photographs of paintings of the interference bands in the models of beams with damage in the form of cracks, cuts in the light of the reinforcing layer of carbon fiber and without it. Figure 4 shows the results of an experiment conducted in pure bending, as in Fig. 5 with the direct cross.

Analisis of the stress fields shows that stress concentration with summit of the inclined crack is lower than with the same load with wertical cut.

The pictures show a sharp decline in the number of lines in amplification patterns carbon. In pure bending at the crack tip-cut on the vertical axis of symmetry of the introduction of carbon-fiber stress decreased by $93 \%$, and the direct cross - at $88 \%$. Near the top of the inclined crack with increased voltage drop was in pure bending $80 \%$, and in the case of direct cross $-84 \%$. 
a)

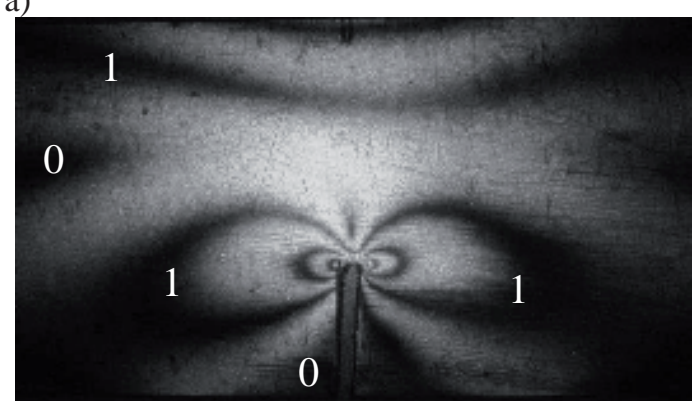

c)

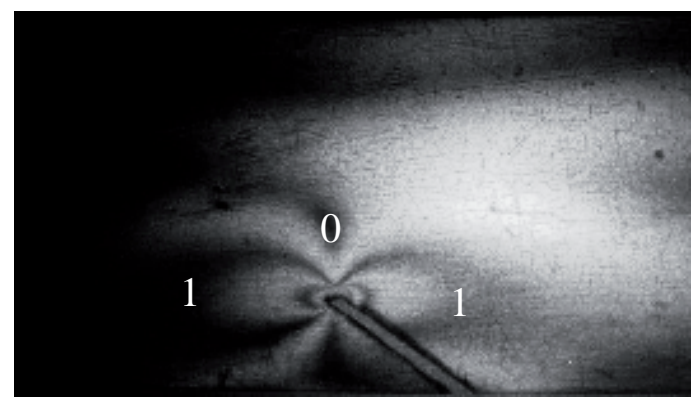

b)

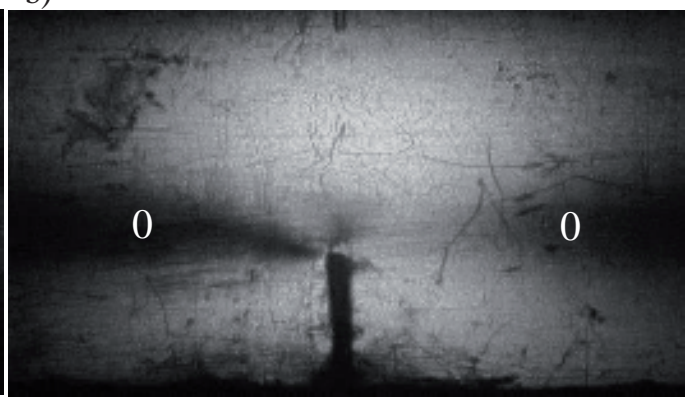

d)

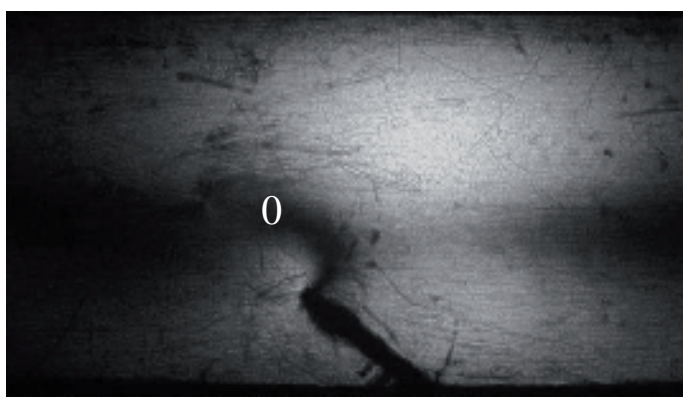

Fig. 4. Pictures of the interference bands in pure bending, $F=0,074 \mathrm{kN}$. Model of a beam with cuts on the vertical axis of symmetry: a) without carbon, b) with carbon fiber.

Model of a beam with an inclined cutting: c) without carbon, d) with carbon plastics

a)

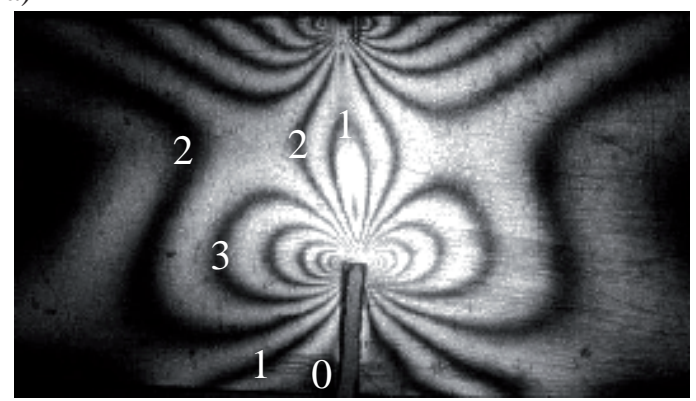

c)

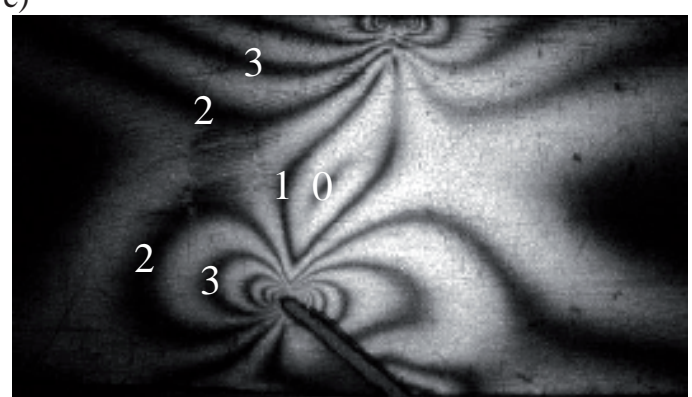

b)

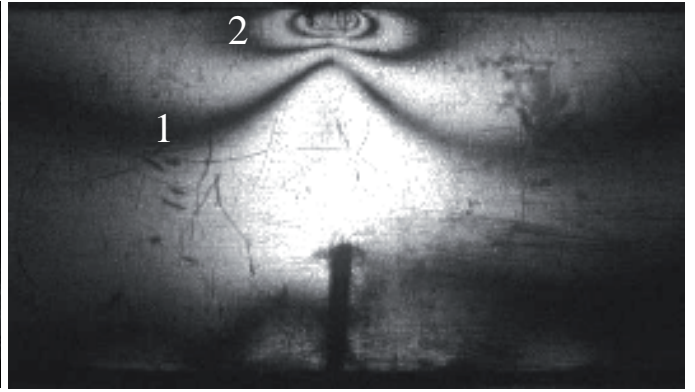

d)

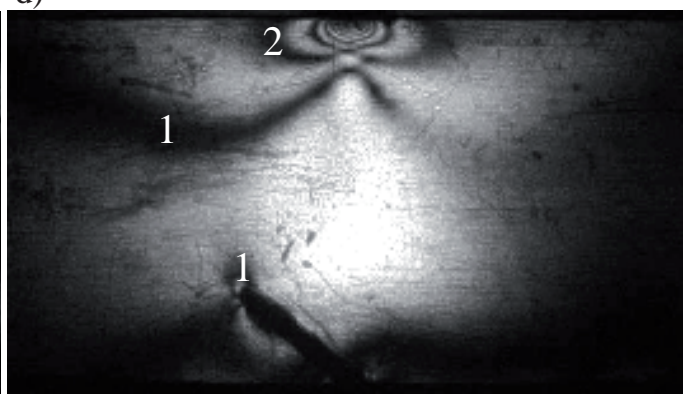

Fig. 5. Pictures of the interference bands in the direct lateral bending, $F=0,147 \mathrm{kN}$. Model of a beam with cuts on the vertical axis of symmetry: a) without carbon fiber, b) with carbon fiber. Model of a beam with an inclined cutting: c) without carbon fiber, d) with carbon plastics 


\section{Conclusions of the work}

With clear and triple - pointed bending inclined crack, as geometric stress concentrator is less dangerous than vertical. Introduction of the inforcing layer permits lower stress on all of the field of the model and lower concentration with summit of the crack.

\section{References}

1. J. Wang A. Int. J. of Solids and Structures 43 (2006)

2. L. Zhang, J. Wang, Int. J. of Solids and Structures 45 (2008)

3. L. Zhang, J. Wang, Int. J. of Adhesion \& Adhesives 29 (2009) 